\title{
Determination of Pesticide Residues in Most Commonly Consumed Leafy Vegetables in Riyadh Region (Al-Kharej Province) \\ Turki Kh. Faraj ${ }^{1,2}$
}

\author{
${ }^{1}$ Prince Sultan Institute for Environmental, Water and Desert Research, and ${ }^{2}$ Soil Science \\ Department, College of Agricultural Sciences, King Saud University, Riyadh, Saudi Arabia
}

talasiri@ksu.edu.sa

\begin{abstract}
A total of 81 samples of various leafy vegetables viz., Rocket (Eruca sativa), Lettuce (Lactuca sativa), Coriander (Coriandrum sativum), Corchorus (Corchorus olitorius), Parsley (Petroselinum crispum), Spinach (Spinacia oleracea), Radish (Raphanus sativus), Dill (Anethum graveolens), Mint (Mentha sachalinensis) and Green onions (Allium cepa) were collected from 20 different areas in Riyadh region of the Kingdom of Saudi Arabia. Liquid-Liquid Extraction of extraction partitioning method and confirmation by gas chromatograph-mass spectrometer for the presence of various pesticide residues was performed. Pesticide residues were detected in all the collected samples with varying concentrations. A variety of pesticides including organochlorines, organophosphates, pyrethroids, carbamates, herbicides, acaricides and insecticides have been identified in the samples. While the residue levels were low for most pesticides, higher levels of chlorpyrifos $(0.123 \mathrm{mg} / \mathrm{kg}$ and resmethrin $(0.1 \mathrm{mg} / \mathrm{kg})$ were found in Rocket, carbaryl $(0.92$ $\mathrm{mg} / \mathrm{kg}$ ) in spinach and corchorus $(0.116 \mathrm{mg} / \mathrm{kg})$, permethrin (total cis + trans permethrin) inlettuce $(0.103 \mathrm{mg} / \mathrm{kg})$ and coriander $(0.126 \mathrm{mg} / \mathrm{kg})$, and cypermethrin in parsley $(0.126 \mathrm{ppm})$. The highest maximum residue limit (MRL) values of pesticide residues on leafy vegetables of 0.10 $\mathrm{mg} / \mathrm{kg}$ were observed for carbaryl in Spinach and Corchorus, whereas in Parsley an MRL of 0.5 $\mathrm{mg} / \mathrm{kg}$ was found. The current research shows that in some leafy vegetables, higher doses of pesticides were found.
\end{abstract}

Keywords: Pesticides, residues, leafy vegetables, Gas Chromatography Mass Spect. Saudi Arabia, Riyadh.

\section{Introduction}

The use of various pesticides in agricultural practices has significantly enhanced the quality and quantity of vegetables and fruits worldwide. However, excessive use of pesticides has caused an increase in contamination of the environment in addition to causing many short and long term health complications some reversible and irreversible (Kaloyanova and El-Batawi, 1991). The detection of large levels of pesticide residues in vegetables and fruits is a serious threat to human and animal health (Damalas and Eleftherohorinos, 2011). Minimising of exposure to environmental toxicants like pesticides especially in consumables remains one of the major objectives of the Ministry of Health in Saudi Arabia. Pesticides are being used worldwide to protect agricultural crops, insects at home and in horticulture. Pesticides belonging to various classes such as organophosphates, organochlorines, pyrethroids and carbamates apart from other herbicides, acaricides, insecticides are used either singly or in combinations of variable concentrations can successfully cater to controlling a wide variety of pests (Sobus et al., 2015). At the same time, at 
least some of the pesticides are not easily biodegradable and/or remain on food products even after processing and thus make into the food chain and ecological systems.

Therefore, measurement of pesticide residues in consumable foods is an essential prerogative in maintaining health standards and thus to minimize the harmful impact of pesticides. The current study thus evaluates the pesticide residues in most commonly used leafy vegetables in Riyadh region of Saudi Arabia. Currently the wide use of pesticides in Saudi Arabia can not only lead to extensive pollution of the environment but also constitutes a potential and/or deliberate risk to human health (El-Saeid, and Shaht 2000; ELSaeid, and Khan (2015), EL-Saeid and Selim (2013), Selim et al., (2011); Khaled et al., 2011). Some investigations reported that the persistence of different pesticides left residual amounts in vegetables with different residue levels (Coats and Yamamoto, 2003; Ripley et al., 2003). The analysis of pesticide residues in foods especially fresh edible fruits and vegetables is very important, because of the potential adverse health and toxic effects of these compounds due to consumption of contaminated foods depend at maximum residue limits (MRLs) and Acceptable Daily Intake (ADI) (FAO/WHO, 1998). It has been reported that pesticide residues in fruits and vegetables can cause severe impact to human health including liver damage, interfering in enzyme production, interaction with drugs and hormones, gastrointestinal intoxication, immunotoxicity and neurotoxicity through cholinesterase inhibition. Therefore, investigation of pesticide residues in vegetables and fruits have become an essential prerequisite for appropriate food quality control procedures.

The analyses of pesticide residues are routinely carried out by means of multi-residue methods based on homogenization of the sample with an appropriate solvent, separation of the liquid portion of the sample from the insoluble material, purification and cleansing by florisil column, followed by the final chromatographic determination procedure (Torres et al., 1996; Albero et al., 2001; Tadeo et al. 2000). The organic solvents commonly used to extract pesticide residues in fresh fruit and vegetables are acetonitrile, Petroleum Ether (PE) and diethyl ether. An extensive clean-up of organic extraction is necessary to reduce the adverse effects related to the quantification of residues, such as the masking of residue peaks by co-eluted matrix component, the occurrence of false positives and/or inaccurate quantitation (Colume et al., 2000; Navarro et al., 2000). To detect the pesticide accurately with high specificity and precision, we have used a modified method for sample preparation and extraction (Schenck and Hobbs, 2004) followed by detection using gas chromatograph-mass spectrophotometer (Fernandez et al., 2000; Rosa et al., 2009; Miguel et al., 2011). The aim of the current study was to monitor the levels of various pesticide residues in some commonly used fresh leafy vegetables collected from various regions of Riyadh, Kingdom of Saudi Arabia. In addition, the Maximum Residue limits (MRL) were analysed in order to compare with the International MRLs.

\section{Materials and Methods}

\subsection{Sample Collection}

Samples of leafy vegetables were collected in sterile polythene bags from some farms in selected areas in Riyadh Region (AlKharej Province). These samples were transported to the laboratory where they were analysed immediately or stored at $4^{\circ} \mathrm{C}$ and analysed within 24 hours.

\subsection{Reagents and Equipment}

All the following pesticides standards were obtained from (Riedel de Haen and Supelco). $1 \mathrm{mg} / \mathrm{ml}$ stock solution of each was 
prepared by dissolving $20 \mathrm{mg}$ of the pure analytical standard in acetone. A single composite standard solution was prepared by diluting with acetone according to limit of detection (LOD). Allstandard solutions were stored in glass-stoppard flasks at $4^{\circ} \mathrm{C}$. Mixed compound calibration solutions were prepared in acetone and they were used as spiking solution. Solvents (residue analysis grade) used were acetone, acetonitrile, petroleum ether and other reagents such as sodium chloride and anhydrous sodium sulphate, florisil 60-100 mesh for residue analysis were also from purchased from (Fluka). The florisil and anhydrous sodium sulphate was activated at $100{ }^{\circ} \mathrm{C}$ overnight and stored in $500 \mathrm{ml}$ glass flask with glass stoppers and stored in oven at $100{ }^{\circ} \mathrm{C}$. The equipment used were a high-speed blender with a stainless steel jar (Waring, USA), a separation funnel shaker (GFL, Germany), a rotavapor, R 215 with cooler circulator chiler B-740 (Buchii, Switzerland), Buchner funnel and chromatographic tubes with Teflon stopcocks and course fritted glass (Agilent, USA) and syringes (Hamilton Bonadus AG, Switzerland). All glassware were rinsed thoroughly using deionization water, then washed with acetone and dried in oven $\left(100-130{ }^{\circ} \mathrm{C}\right)$ over night.

\subsection{Extraction and Partitioning Method}

The pieces leafy vegetable samples $(100 \mathrm{~g})$ were placed in a stainless steel $1 \mathrm{~L}$ jar and $200 \mathrm{ml}$ of acetonitrile and $10 \mathrm{~g}$ of celite will be extracted. The mixture was filtered through Buchner funnel fitted with shark-skin filter paper into a $500 \mathrm{ml}$ suction flask. An aliquot of organic matter was transferred to a 1L separator funnel and $100 \mathrm{ml}$ of PE was added. The mixture was vigorously shaken for $1-2$ minutes and then $100 \mathrm{ml}$ of saturated $\mathrm{NaCl}$ solution and $600 \mathrm{ml}$ water was added. The mixture was vigorously mixed and the separator funnel was held in a horizontal position for a few minutes. The aqueous layer was discarded and the solvent layer was washed with twice the amount of distilled water and this washed layer was transferred into a $100 \mathrm{ml}$ beaker and washed with $15 \mathrm{~g}$ anhydrous sodium sulphate. Finally, the extract was concentrated to $5 \mathrm{ml}$ volume and transferred directly to a florisil column (Selim et al., 2011).

\subsection{Recovery Experiment}

For recovery studies, $100 \mathrm{~g}$ homogenized sample was spiked prior to determination procedure by addition of a mixture of standard pesticides solution $0.1 \mu \mathrm{g} / \mathrm{ml}$ of each compound. Spiked samples were left to stand for $30 \mathrm{~min}$. to allow pesticide to absorb into the sample. Samples were extracted according to the method described above. The recoveries \% (Table 1) and limit of detection (LOD) (Table 2) data for tested pesticides are calculated.

Table 1. Recovery \% and limits of detection (LOD $\mu \mathrm{g} / \mathrm{kg}$ ) for tested pesticides in leafy Vegetable Samples.

\begin{tabular}{|l|c|c|c|}
\hline \multicolumn{1}{|c|}{ Pesticides } & $\begin{array}{c}\text { Spiking level } \\
(\boldsymbol{\mu g} / \mathbf{g}) .\end{array}$ & LOD $(\boldsymbol{\mu g} / \mathbf{g})$ & $\begin{array}{c}\text { Recovery } \\
\mathbf{\%}\end{array}$ \\
\hline Mevinphos & 0.10 & 0.090 & 89.6 \\
\hline Ethoprophos & 0.10 & 0.050 & 93.4 \\
\hline Lindan & 0.10 & 0.010 & 101.3 \\
\hline Iprobenfos & 0.10 & 0.040 & 104.7 \\
\hline Chlorpyrifos & 0.10 & 0.030 & 98.6 \\
\hline Carbaryl & 0.10 & 0.030 & 98.5 \\
\hline Linuron & 0.10 & 0.040 & 93.8 \\
\hline
\end{tabular}




\begin{tabular}{|l|l|l|l|}
\hline Endosulfan & 0.10 & 0.090 & 48.9 \\
\hline Resmethrin & 0.10 & 0.030 & 88.3 \\
\hline Phosmet & 0.10 & 0.030 & 88.6 \\
\hline Fenoxycarb & 0.10 & 0.070 & 89.8 \\
\hline Tetramethrin & 0.10 & 0.020 & 85.2 \\
\hline Amitraz & 0.10 & 0.030 & 92.9 \\
\hline Azenophos-ethyl & 0.10 & 0.030 & 94.6 \\
\hline Permethrin & 0.10 & 0.020 & 98.8 \\
\hline Cyfluthrin & 0.10 & 0.040 & 89.7 \\
\hline Cypermethrin & 0.10 & 0.030 & 93.4 \\
\hline Deltamethrin & 0.10 & 0.050 & 101.3 \\
\hline
\end{tabular}

Table 2. Averages of pesticide residues, Standards Deviation and number of samples of leafy vegetables. Scientific Name.

\begin{tabular}{|c|c|c|c|c|c|}
\hline $\begin{array}{c}\text { Common } \\
\text { Name }\end{array}$ & $\begin{array}{l}\text { Scientific } \\
\text { Name }\end{array}$ & $\begin{array}{c}\text { No. of } \\
\text { Samples }\end{array}$ & Pesticide Name & $\begin{array}{c}\text { Averages } \\
(\mu \mathrm{g} / \mathrm{g})\end{array}$ & St. D \\
\hline \multirow{5}{*}{ Rocket } & \multirow{5}{*}{ Eruca sativa } & \multirow{5}{*}{$\underline{8}$} & Cyfluthrin & 0.013 & 0.002 \\
\hline & & & Lindane & 0.001 & 0.001 \\
\hline & & & Iprobenfos & 0.023 & 0.002 \\
\hline & & & Chloropyrifos & 0.123 & 0.003 \\
\hline & & & Resmethrin & 0.101 & 0.001 \\
\hline \multirow{5}{*}{ Lettuce } & \multirow{5}{*}{ Lactuca sativa } & \multirow{5}{*}{$\underline{9}$} & Mevinphos & 0.001 & 0.002 \\
\hline & & & Deltamethrin & 0.048 & 0.004 \\
\hline & & & Tetramethrin & 0.024 & 0.003 \\
\hline & & & $\begin{array}{c}\text { Azinophos- } \\
\text { ethyl }\end{array}$ & 0.008 & 0.001 \\
\hline & & & Permethrin & 0.104 & 0.006 \\
\hline \multirow{4}{*}{ Coriander } & \multirow{4}{*}{$\frac{\text { Coriandrum }}{\text { sativum }}$} & \multirow{4}{*}{$\underline{8}$} & Resmethrin & 0.014 & 0.006 \\
\hline & & & Permethrin & 0.126 & 0.019 \\
\hline & & & Lindane & 0.005 & 0.003 \\
\hline & & & Linuron & 0.064 & 0.018 \\
\hline \multirow{4}{*}{ Corchorus } & \multirow{4}{*}{$\frac{\text { Corchorus }}{\text { olitorius }}$} & \multirow{4}{*}{$\underline{8}$} & Endosulfan & 0.013 & 0.001 \\
\hline & & & Carbaryl & 0.117 & 0.002 \\
\hline & & & Permethrin & 0.003 & 0.001 \\
\hline & & & Chloropyrifos & 0.006 & 0.004 \\
\hline \multirow{4}{*}{ Parsley } & \multirow{4}{*}{$\frac{\text { Petroselinum }}{\text { crispum }}$} & \multirow{4}{*}{$\underline{8}$} & Amitraz & 0.002 & 0.002 \\
\hline & & & Cyfluthrin & 0.009 & 0.002 \\
\hline & & & Cypermethrin & 0.168 & 0.038 \\
\hline & & & Ethoprophos & 0.001 & 0.001 \\
\hline \multirow{4}{*}{ Spinach } & \multirow{4}{*}{$\frac{\frac{\text { Spinacia }}{\text { oleracea }}}{\text { le }}$} & \multirow{4}{*}{$\underline{8}$} & Carbaryl & 0.920 & 0.048 \\
\hline & & & Endosulfan & 0.003 & 0.002 \\
\hline & & & Linuron & 0.005 & 0.004 \\
\hline & & & Phosmet & 0.012 & 0.001 \\
\hline \multirow{2}{*}{ Mint } & \multirow{2}{*}{$\frac{\text { Mentha }}{\text { sachalinensis }}$} & \multirow[b]{2}{*}{$\underline{8}$} & Fenoxycarb & 0.001 & 0.001 \\
\hline & & & Permethrin & 0.075 & 0.004 \\
\hline \multirow{2}{*}{ Dill } & \multirow{2}{*}{$\begin{array}{c}\text { Anethum } \\
\text { graveolens }\end{array}$} & \multirow[b]{2}{*}{$\underline{8}$} & Cyfluthrin & 0.008 & 0.001 \\
\hline & & & Resmethrin & 0.003 & 0.002 \\
\hline Radish & $\frac{\text { Raphanus }}{\text { sativus }}$ & $\underline{8}$ & Endosulfan & 0.004 & 0.002 \\
\hline Onion & Allium cepa & $\underline{8}$ & Permethrin & 0.002 & 0.002 \\
\hline
\end{tabular}




\subsection{Pesticide Residues Measurement by Chromatographic Analysis}

Gas chromatograph-mass spectrometer (Aglient model 6890N) coupled with quadrupole mass spectrometer (model 5975B) with a GC column HP-5MS 5\% phenyl - 95\% methyl siloxane, $30 \mathrm{~m} \times 0.25 \mathrm{~mm}$ id $\times 0.25 \mu \mathrm{m}$ film thickness was used. GC operating conditions were splitless injection, injector temperature $250{ }^{\circ} \mathrm{C}$, helium carrier gas ( 99.9999 purity) at flow rate $0.9 \mathrm{ml} / \mathrm{min}$ with column head pressure 7.4 psi, oven temperature from $70{ }^{\circ} \mathrm{C}$ ( 2 min hold), than raised to $130{ }^{\circ} \mathrm{C}$ at the rate $\left(25^{\circ} \mathrm{C} / \mathrm{min}\right)$ afterwards raised to $220{ }^{\circ} \mathrm{C}$ at $\left(2{ }^{\circ} \mathrm{C} / \mathrm{min}\right)$ and then raised to $280{ }^{\circ} \mathrm{C}$ at $\left(10{ }^{\circ} \mathrm{C} / \mathrm{min}\right)$ and eventually (4.6 min hold). The sample was injected in splitless modes. The MS system was routinely set in selective ion monitoring (SIM) mode and each compound was quantified based on peak area using one target and one or two qualifier ion. Mass spectrometer parameter was set as follows: electron impact ionization mode with $70 \mathrm{eV}$ electron energy, scan mass range 100-400 at $0.62 \mathrm{sec} / \mathrm{cycle}$. Ion source temperature $230{ }^{\circ} \mathrm{C}$, MS quad temperature $150{ }^{\circ} \mathrm{C}$, EM voltage 1450 and solvent delay 4 min. An appropriate aliquot $(2 \mu \mathrm{l})$ of samples was injected in Gas Chromatography Mass spectrumetry under the mentioned conditions and then pesticides residues were identified by comparison of retention time values with reference standard. Confirmation of results was performed using selected ion monitoring (SIM) mode, one is the quantifier and the qualifying ion (Selim et al., 2011; Tuija et al., 2007).

\section{Results}

\subsection{Concentration of Pesticide Residues in Leafy Vegetables}

Pesticide residues in this study were identified in all the collected samples with varying concentrations. Mixtures of pesticides were identified in most leafy vegetables except Radish and green onion where only endosulfan and permethrin were used respectively. Pesticides belonging to all major categories such as organochlorines, organophosphates, pyrethroids, carbamates, herbicides, acaricides and insecticides have been identified in the samples. The residue levels for most leafy vegetables was less $(<0.05 \mathrm{mg} / \mathrm{kg})$ but higher levels of chlorpyrifos $(0.123 \mathrm{mg} / \mathrm{kg})$ and resmethrin $(0.1 \mathrm{mg} / \mathrm{kg})$ were found in Rocket. Carbaryl $(0.92 \mathrm{mg} / \mathrm{kg})$ in spinach and corchorus $(0.116 \mathrm{mg} / \mathrm{kg})$, permethrin in lettuce $(0.103 \mathrm{mg} / \mathrm{kg})$ and coriander $(0.126 \mathrm{mg} / \mathrm{kg})$, and cypermethrin in parsley $(0.126 \mathrm{mg} / \mathrm{kg})$ (Fig. 1 and 2).

When the percentage of pesticide use was evaluated, it has been found that approximately $50 \%$ pesticides used belonged to carbamate class (carbaryl) followed by $36 \%$ pyrethroids and $14 \%$ others including organophosphates, acaricides, herbicides, and insecticides (Fig. 3).

\subsection{Limit of Detection of Pesticide Residues Identified in the Current Study}

The limit of detection (LOD) for the pesticides used in the current study was evaluated. The results showed that the highest LOD was for Cypermethrin (0.1) followed by Mevinphos (0.09) and Endosulfan (0.09). An LOD value of 0.07 was found for Fenoxycarb, $0.05 \mathrm{mg} / \mathrm{kg}$ for Deltamethrin and Ethoprophos. The LOD values for Cyfluthrin, Iprobenfos and Linuron was 0.04. Chlorpyrifos, Resmethrin, Azinophos-ethyl, Carbaryl, Amitraz and Phosmet had LOD values of 0.03 . Rest of the pesticides had LOD values below 0.02 (Fig. 4).

\subsection{Maximum Residue Limit of Pesticides Found in Leafy Vegetables}

The highest maximum residue limit (MRL) values of pesticide residues on leafy vegetables of 10 were observed for carbaryl in Spinach and Corchorus, whereas in Parsley an MRL of 5 was 
found for Cypermethrin. The MRL values 2 were found for Deltamethrin, Permethrin and
Endosulfan. The MRL values of most other pesticides were found to be $0.5 \mathrm{mg} / \mathrm{kg}$ (Fig. 5).

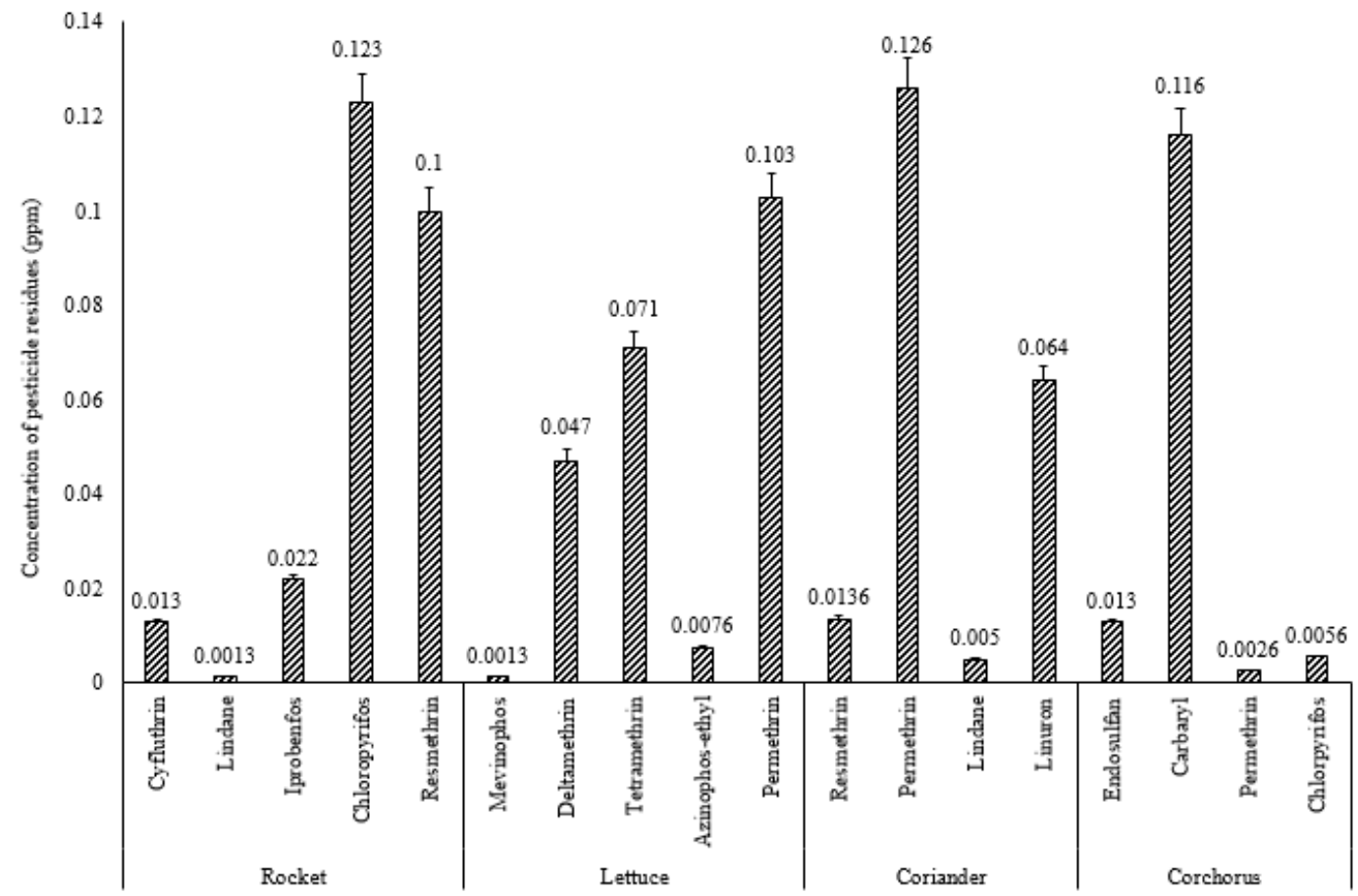

Fig. 1. Concentrations of various pesticide residues in Rocket, Lettuce, Coriander and Corchorus. Data are presented as mean+/-SD. All values are in ppm.

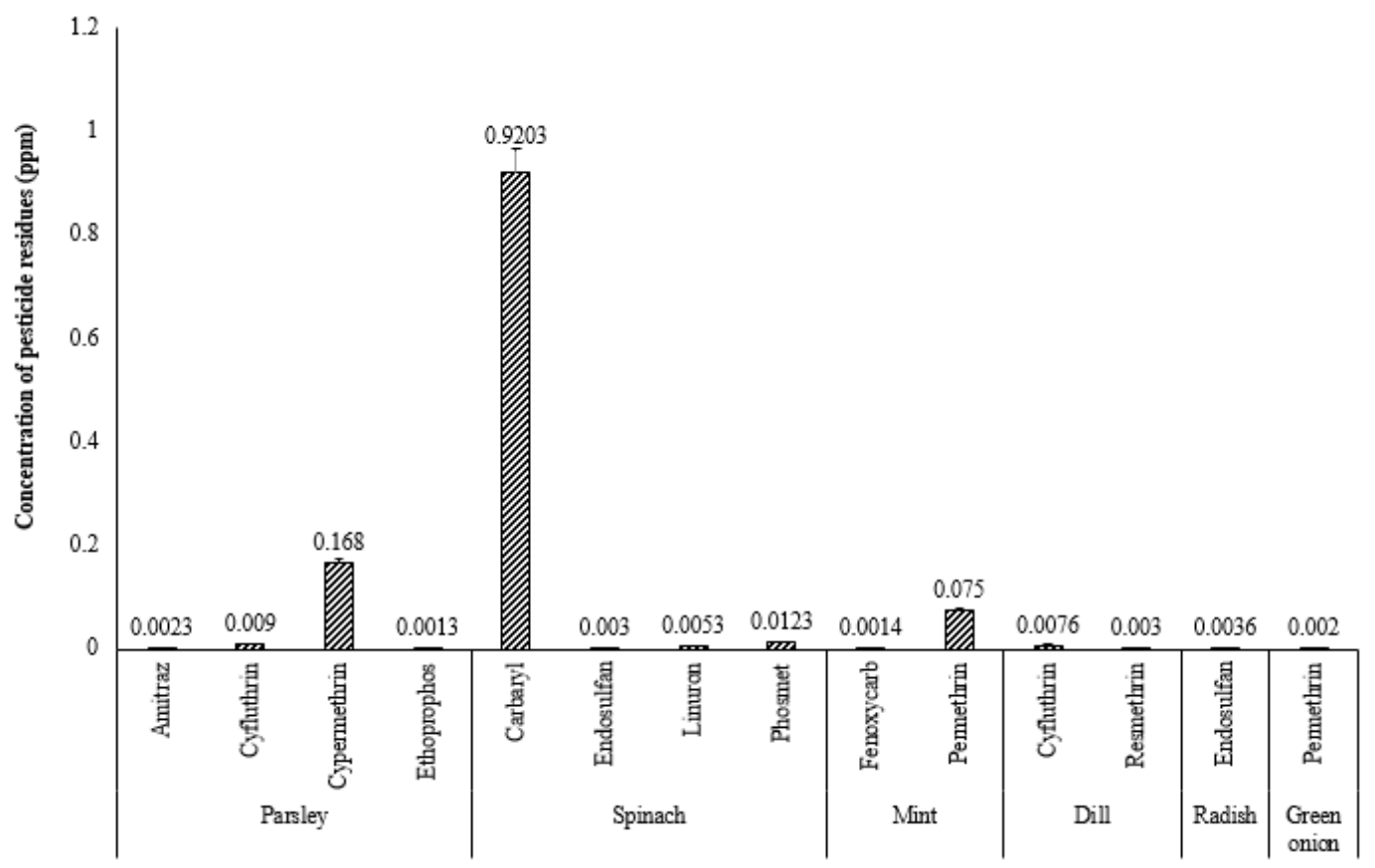

Fig. 2. Concentrations of various pesticide residues in Parsley, Spinach, Mint, Dill, Radish, and Green onion. Data are presented as mean+/-SD. All values are in ppm. 


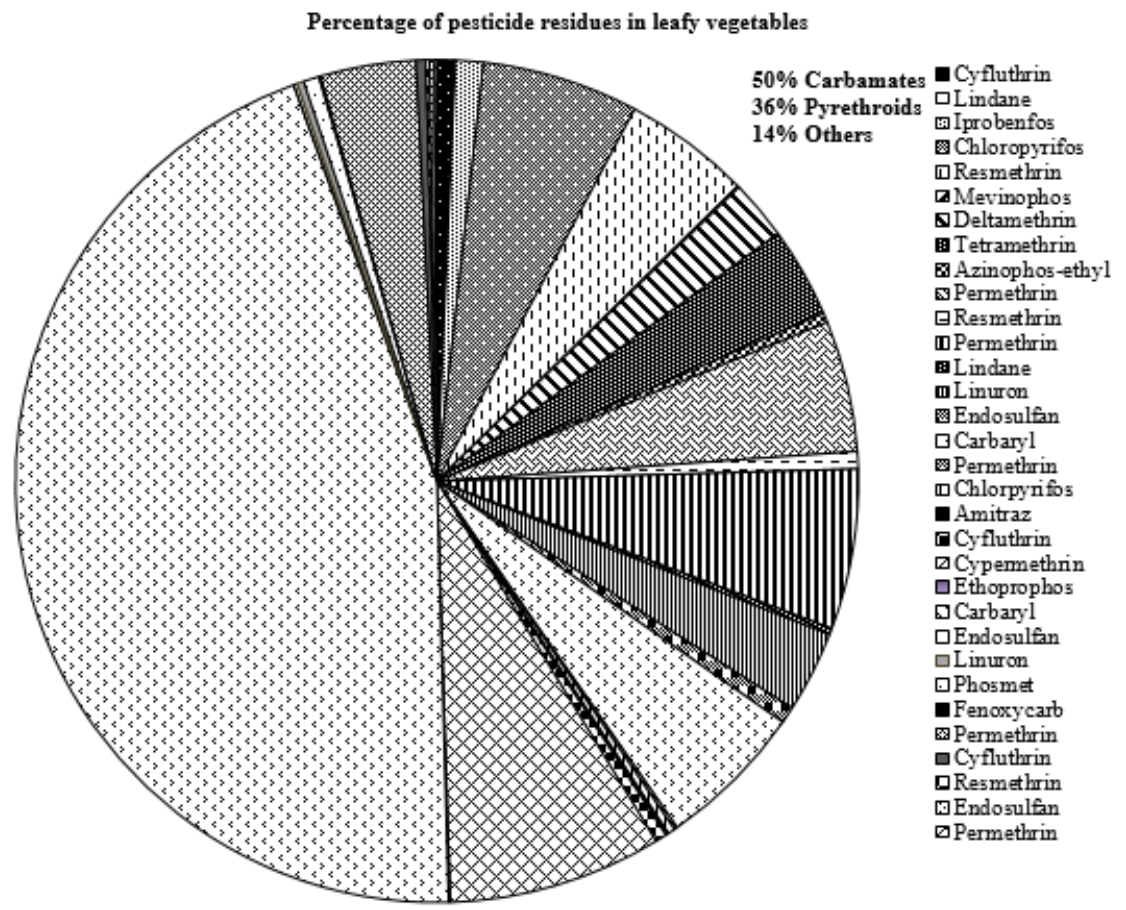

Fig. 3. Percentages of various pesticide residues in leafy vegetables investigated in the current study. The order of pesticide usage was carbamates $(50 \%)>$ pyrethroids $(36 \%)>$ others $(14 \%)$. Others include organophosphate pesticides, insecticides, acaricides, and herbicides.

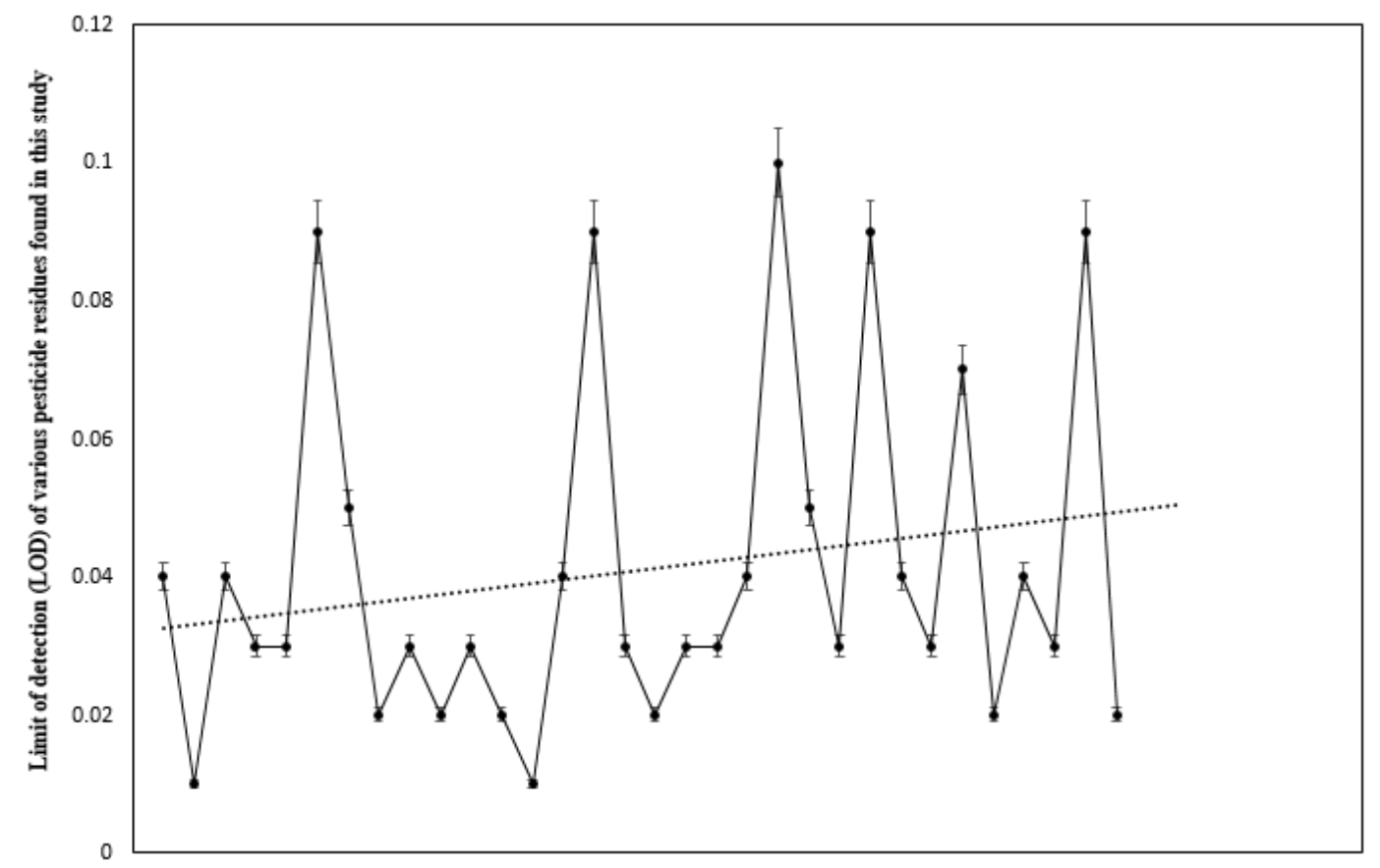

Fig. 4. The limit of detection (LOD) of various pesticide residues in leafy vegetables in the current study. 


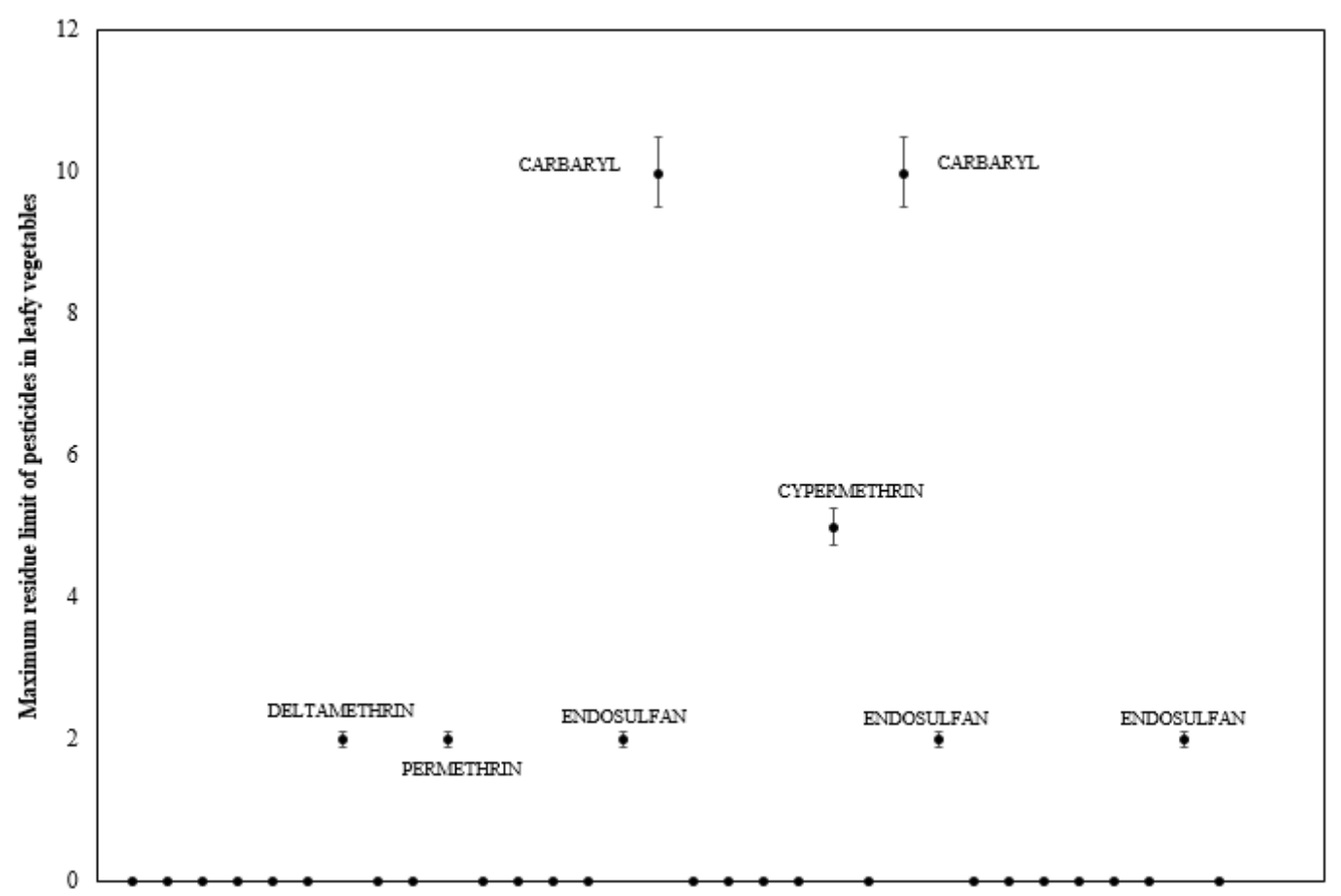

Fig. 5. Maximum residue level of various pesticide residues found in leafy vegetables in the current study. Carbaryl showed the highest MRL, followed by Cypermethrin, Deltamethrin, Endosulfan and Permethrin.

\section{Discussion}

A total 81 samples of leafy vegetables (Rocket, Lettuce, Coriander, Corchorus, Parsley, Spinach, Radish, Dill, Mint and Green onions) were collected from 20 different regions of Riyadh. All samples were processed and analysed using the GCMS system. Pesticide residues in this study were interestingly found in all the collected leafy vegetables. Almost in all cases, the farmers used a mixture of pesticides belonging to various chemical classes except in vegetables like Radish and green onion.

Health-based recommendations or guidelines are based on data obtained from toxicological studies on experimental animals, and sometimes on observations in man. In order to evaluate the acceptability of a proposed MRL, it is necessary to compare the dietary intake of pesticide residues, which is calculated on the basis of MRL, with the ADI.
The dietary intake is calculated by multiplying each MRL with the quantity of the corresponding diet component, followed by summation of the residue quantities obtained. It should be noted that the use of the MRL in the calculation of total intake might lead to a higher value than the actual intake, since the actual residue levels will often be lower than the recommended MRLs (Van Leeuven, 1997).

Farmers used a mixture of organochlorines, organophosphates, pyrethroids, carbamates, herbicides, acaricides andinsecticides for cultivation. However, most of the leafy vegetables showed pesticide residues of $<0.05$ ppm. In certain leafy vegetables very high levels of carbaryl, chlorpyrifos, resmethrin, permethrin and cypermethrin were found. Interestingly, pesticides which have been categorized as restricted use by the Ministry of Agriculture, Kingdom of Saudi Arabia eg: carbaryl, chlorpyrifos and endosulfan were 
used on leafy vegetables. Majorly pesticides of the carbamate group were used $(50 \%)$ followed by pyrethroids (36\%) and others (14\%). Most of the pesticides showed MRL values of 0 , while, the highest MRL values observed were 10 for carbaryl and 5 for Cypermethrin. MRL values 2 were found for Deltamethrin, Permethrin and Endosulfan.

In the analysed samples 20 different pesticides were found at various concentrations. A combination of 5 pesticides were used for cultivation of Rocket and Lettuce. Four pesticides were used for cultivation of coriander, corchorus, parsley and spinach. The combination of two pesticides was used in dill and mint while only one pesticide each was used for cultivation of radish and green onions. The present study showed a high incidence of pesticide residues (mostly carbamates, organochlorines and pyrethroids) in analysed leafy vegetable samples.

In the current study we also used the Liquid-Liquid Extraction and GCMS method which helped in easy, simple and rapid extraction method in addition to high sensitivity detection reliable analysis for all tested pesticide residues (Yang et al., 2012; Subhash et al., 2014; Soparat et al., 2015). The results obtained were in accordance to quality control requirements and all experiments were validated. These methods helped in quick analysis within a shorter time and allowed for efficient pesticide monitoring. The LOD values obtained were found to be highest for Cypermethrin (0.1), Mevinphos (0.09) and Endosulfan (0.09) followed by Fenoxycarb (0.07) and $0.05 \mathrm{mg} / \mathrm{kg}$ for Deltamethrin and Ethoprophos.

In the present study, the Liquid-Liquid Extraction method was used for sample preparation and GCMS analysis was established. This combination helped in achieving highly sensitive results that are easily reproducible. The contamination levels of pesticide residues observed in this study on leafy vegetables can pose a serious threat to public health if proper washing or processing conditions are not applied. The high MRL values observed for carbaryl, pyrethroids and organochlorines observed in this study indicate that these pesticides may pose a possible public health problem. The results highlight the necessity for consistent monitoring for pesticide residues for these vegetables before being marketed to the public.

\section{Acknowledgment}

The author extends his appreciation to the Deanship of Scientific Research at King Saud University for funding this work through research group No (RG- 1439-86).

\section{References}

Albero, B., Brunte, C.S. and Tadeo, J.L. (2001). Multiresidue determination of pesticides in honey by matrix solid-phase dispersion and gas chromatography with electron- capture detection. J. AOAC Int. 84: 11651171.

Coats, J.R. and Yamamoto, H. (2003). Environmental Fate and Effects of Pesticides. American Chemical Society, Washington, D.C., 300 pp.

Colume, A., Cardenas, S., Gallego, M. and Valcarcel, M. (2000). Simplified method for the determination of chlorinated fungicides and insecticides in fruits by gas chromatography. J. Chromatogr, A 882: 193-203.

Cooper, J. and Dobson, H. (2007). The benefits of pesticides to mankind and the environment", Crop Protection, 26: $1337-1348$

Damalas, C.A. and Eleftherohorinos, I.G. (2011). Pesticide Exposure, Safety Issues, and Risk Assessment Indicators. International Journal of Environmental Research and Public Health, 8: 1402-1419.

EL-Saeid, M.H. and Khan, H. (2015). Determination of pyrethroid insecticides in crude and canned vegetable samples by supercritical fluid chromatography. International Journal of Food Properties, 18: 1119-1127.

EL-Saeid, M.H. and Selim M.T. (2013). Multi-residues Analysis of 86 Pesticides Using Gas Chromatography Mass Spectrometry: II- Non-Leafy Vegetables. J. of Chemistry, ID727149: $10 \mathrm{p}$.

EL-Saeid, M.H. and Shaht, M. (2000). Detection of pesticide residues and heavy metals in some fresh fruits and vegetables collected from Cairo. First Mansoura Conf. of Food and Dairy Tech., Cairo, Egypt, pp. 183-203. 
FAO/WHO (1998). Food Standards Program of Codex Alimentarius Commission about pesticide residues in food-Maximum residue limits. Vol. 2 B, Rome.

Fenner, K., Canonica, S., Wackett, L.P. and Elsner, M. (2013). "Evaluating Pesticide Degradation in the Environment: Blind Spots and Emerging Opportunities". Science, 341: 752.

Fernandez, M., Pico, Y. and Manes, J. (2000). Determination of carbamate residues in fruits and vegetables by matrix solid-phase dispersion and liquid chromatography-mass spectrometry. J. Chromatogr, A 871: 43-56.

Kaloyanova, F.P. and El-Batawi, M.A. (1991). Human Toxicology of Pesticides. International standard book, ISBN \# 0-8493-5192-8. Library of Congress, CRC Press Inc.

Kamrin, M.A. (1997). Pesticide Profiles: Toxicity, Environmental Impact, and Fate. CRC Press.

Khaled A. O., Al-Humaid, A.I., Al-Rehiayani, S. M. and Al-Redhaiman, K. N. (2011). Estimated daily intake of pesticide residues exposure by vegetables grown in greenhouses in Al-Qassim region, Saudi Arabia Food Control., 22: 947-953.

Miguel Á. G., Borges, J.H., Ravelo-Pérez, L. M. and Rodríguez-Delgado, M. Á. (2011). Insecticides extraction from banana leaves using a modified QuEChERS method. Food Chemistry, 125: 1083-1090.

Navarro, S., Barba, A., Navarro, G., Vela, N. and Oliva, J., (2000). Multiresidue method for the rapid determinationin grape, must and wine-of fungicides frequently used on vineyards. J. Chromatogr., A 882: 221-229.

Van Leeuven (1997). Setting toxicological standards for food safety J. de Vries (Ed.), Food Safety and Toxicity, CRC Press, Boca Raton, FL (1997), pp. 255-266.

Ripley, B.D., Ritcey, G.M., Harris, C.R., Denomme, M.A., and Lissemore, L.I. (2003). Comparative persistence of pesticides on selected cultivars of specialty vegetables. $J$. Agric. Food Chem., 51: 1328-1335.

Rosa M. G., Cancho-Grande, B. and Simal-Gándara, J., (2009). Multiresidue determination of 11 new fungicides in grapes and wines by liquid-liquid extraction/clean-up and programmable temperature vaporization injection with analyte protectants/gas chromatography/ion trap mass spectrometry. Journal of Chromatography, A. 1216: 60336042 .
Schenck F. J. and Hobbs, J.E. (2004). Evaluation of the Quick, Easy, Cheap, Effective, Rugged, and Safe (QuEChERS) Approach to Pesticide Residue Analysis". Bulletin of Environmental Contamination and Toxicology (New York: Springer) 73: 24-30.

Selim, M.T., EL-Saeid, M.H. and Al-Dossari, I.M. (2011). Multi-residues Analysis of Pesticides Using Gas Chromatography Mass Spectrometry: I- Leafy Vegetables. Research J. of Environmental Sciences, 5: 248-258.

Sobus, J.R., DeWoskin, R.S., Tan Y.M., Pleil, J.D., Phillips, M.B., Georg, B.J., Christensen, K., Schreinemachers, D.M., Williams, M.A., Cohen Hubal, E.A. and Edwards, S.W. (2015). Uses of NHANES Biomarker Data for Chemical Risk Assessment: Trends, Challenges, and Opportunities. Environ Health Perspect. http://dx.doi.org/10.1289/ehp.1409177.

Soparat, Y., Meecharoenb, W. and Leepipatpiboona, N. (2015). New practical approach for using an analyte protectant for priming in routine gas chromatographic analysis. Food Control, 48: 25-32.

Subhash, C., Mahindrakar, A.N. and Shinde, L.P. (2014). Gas Chromatography- Mass Spectrometry determination of Pesticide Residue in Fruits. International Journal of ChemTech Research CODEN (USA): 6: 124-130.

Tadeo, J.L., Sanchez-Brunete, C., Perez, R.A. and Fernandez, M.D. (2000). Analysis of herbicide residues in cereals, fruits and vegetables. J. Chromatogr, A 882: 175-191.

Torres, C.M., Pico, Y. and Manes, J. (1996). Determination of pesticide residues in fruit and vegetables. $J$. Chromatogr. A 754: 301-331.

Tuija, P., Gun, B., Paula, F., Ulla, P. and Bengt-Goran O. (2007). Analysis of pesticide residues in fruit and vegetables with ethyl acetate extraction using gas and liquid chromatography with tandem mass spectrometric detection. Analytical and Bioanalytical Chemistry, 389(6): 1773- 1789.

Yang, C., Al-Taher, F. R., Juskelis, J. W., Wong, K., Zhang, D. G., Hayward, J., Zweigenbaum, J., Stevens, N. and Cappozzo, J. (2012). Multiresidue Pesticide Analysis of Dried Botanical Dietary Supplements Using an Automated Dispersive SPE Cleanup for QuEChERS and High-Performance Liquid Chromatography-Tandem Mass Spectrometry. J. Agric. Food Chem., 60: 9991-9999. 
تحديد منتقيات المبيدات الحشرية في الخضروات الورقية الأكثز استخدامًا في منطقة الرياض (محافظة الخرج)

تركي خلوفة فرج"r

' معهُ الأمبر سلطان لأبحاث البيئة والمياه والصحراء، و'َقم علم التربة، كلية الزراعة والأغذية، جامعة الملك سعود، الرياض، المملكة العربية السعودية

talasiri@ksu.edu.sa

المستخلص. تم جمع 1 1 عينة من الخضروات الورقية المختلفة من ·r موقعًا من منطقة الرياض بالمملكة العربية السعودية، وهي: جرجير ، وخس، وكزبرة، وملوخية، وبقدونس، وسبانخ،

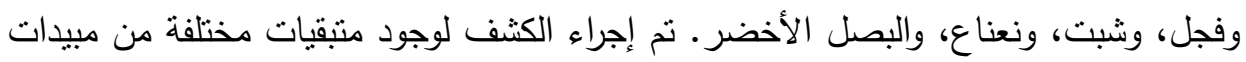

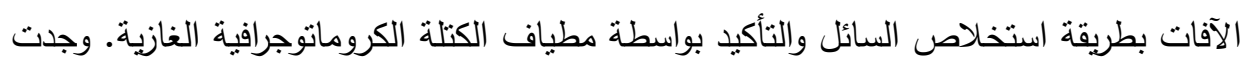
بقايا المبيدات في جميع العينات التي تم جمعها بتركيزات مختلفة، وقد نم تحديد مجموعة منتوعة من المبيدات الحشرية في العينات، وهي: الكلور العضوي، والفوسفات العضوي، والبيرثرويدات، والكاربامات، ومبيدات الأعثاب، والمبيدات الحشرية. ففي حين أن مستويات المتنقيات كانت

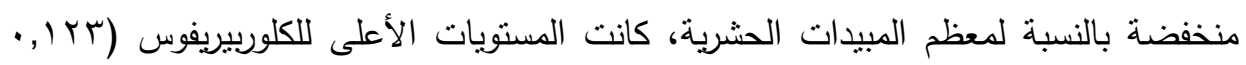

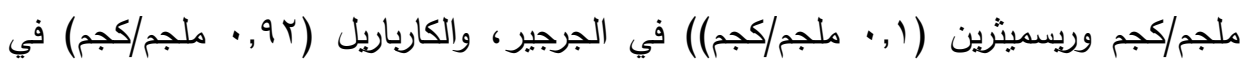
السبانخ و (17 1, · ملجم/كجم) في الملوخية، والبيرميثرين (مجموع cis + بيرميثرين غير

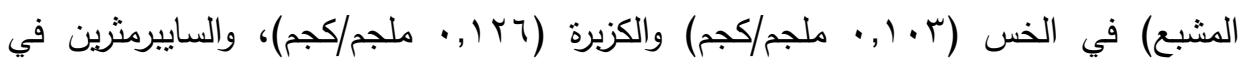
البقدونس (Tr M , · جزء في المليون). وقد لوحظت قيم الحد الأفصى لمتبقيات المبيدات (MRL) على الخضروات الورقية، والبالغ قدرها • (1, • ملجم/كجم للكرباريل في السبانخ والملوخية، بينما وجد في البقدنس حد أقصى قدره ه, · ملجم/كجم. ويظهر البحث الحالي وجود جرعات عالية

$$
\text { من المبيدات الحشرية في بعض الخضروات الورقية. }
$$

كلمات مفتاحية: المبيدات الحشرية، المتنقيات، الخضروات الورقية، تحليل الغاز الكروماتوغرافي، السعودية، الرياض. 
